\title{
Schisandra chinensis polysaccharides attenuate the growth of tuberculosis bacilli in rats via immunity enhancement
}

\author{
Jian Huang ${ }^{1}$, Li Ren ${ }^{2 \star}$, Shaobin Zhang ${ }^{1}$, Ze Peng ${ }^{1}$ \\ ${ }^{1}$ Department of Surgery, Wuhan Jinyintan Hospital, Dong Xihu District, Wuhan, Hubei, 430000, ${ }^{2}$ The Fourth Medical Ward, \\ Wuhan Red Cross Hospital,Jianghan District, Wuhan, Hubei 430015, People's Republic of China
}

*For correspondence: Email: RJaynandl@yahoo.com

Sent for review: 20 April 2018

Revised accepted: 26 July 2018

\begin{abstract}
Purpose: To evaluate the effect of Schisandrachinensis polysaccharides (SCPP11) on the growth of tuberculosis (TB) bacilli in a rat model.

Methods: Tuberculosis (TB) was induced by administration of colonies of tubercle bacilli via the inhalation route. SCPP11 was administered at separate doses of 25,50 and $100 \mathrm{mg} / \mathrm{kg}$ to different rat groups, p.o., for 4 weeks. Untreated rats served as TB control. At the end of treatment, assessments were made on the effect of SCPP11 on colony forming unit (CFU), cytokine levels, and population of immune cells present in lung tissue homogenates of the TB-infected rats.

Results: The CFU of TB bacilli was significantly reduced in the lung tissues of SCPP11-treated group, when compared to untreated TB control group. Moreover, SCPP11 attenuated lung tissue levels of inflammatory cytokines, and significantly enhanced immunity, relative to the TB control group.

Conclusion: These results indicate that SCPP11 ameliorates TB by suppressing the growth of tuberculosis bacilli.
\end{abstract}

Keywords: Schisandra chinensis, Polysaccharides, Immune cells, Tuberculosis bacilli, Cytokines

\begin{abstract}
This is an Open Access article that uses a funding model which does not charge readers or their institutions for access and distributed under the terms of the Creative Commons Attribution License (http://creativecommons.org/licenses/by/4.0) and the Budapest Open Access Initiative (http://www.budapestopenaccessinitiative.org/read), which permit unrestricted use, distribution, and reproduction in any medium, provided the original work is properly credited.

Tropical Journal of Pharmaceutical Research is indexed by Science Citation Index (SciSearch), Scopus, International Pharmaceutical Abstract, Chemical Abstracts, Embase, Index Copernicus, EBSCO, African Index Medicus, JournalSeek, Journal Citation Reports/Science Edition, Directory of Open Access Journals (DOAJ), African Journal Online, Bioline International, Open-J-Gate and Pharmacy Abstracts
\end{abstract}

\section{INTRODUCTION}

Tuberculosis (TB) is caused by tubercle bacilli infection, which causes the death of approximately 1.2 million people every year throughout the world [1]. Available literature reveals that immune-compromised people are readily prone to TB reactivation [2]. Microbicidal activity of alveolar macrophages are activated due to secretion of chemokines and TNF- $\alpha$ which recruit T-lymphocytes in the lung granulomas during respiratory infection of MT [3]. Nonoxidative and oxidative mechanisms are used by alveolar macrophages to kill MT bacteria [4]. Digestive enzymes and acidic $\mathrm{pH}$ within the lysosomes of macrophages also promote bacterial death [5].

In multiple drug-resistant TB (MDR-TB), the management of TB is made difficult due to development of resistance against anti-TB agents by tubercle bacteria [6]. The MT bacteria 
resistance is developed by altering the acidification phagosome and fusion of phagolysosome [7]. In view of the problems posed by bacterial resistance, there is need for development of new drugs for the management of MDR-TB.

In the last few decades, alternative medicines have shown great potential in the management of chronic disorders. Schisandra chinensis (Turcz.) Baillis traditionally used for medicinal purposes in China [8]. It is used for enhancing the secretion of body fluids, and as a kidney tonic, and also for calming the mind [9]. It is also used for the management of neurasthenia and hepatitis [10]. Several pharmacologically active polysaccharides are present in Schisandra chinensis [11]. These polysaccharides are known to possess broad spectrum therapeutic uses, which include immunomodulatory activities [11]. Studies have revealed that Schisandra chinensis polysaccharides promote the secretion of inflammatory cytokines, leading to the activation of NK cells, macrophages and lymphocytes [12]. Moreover, the polysaccharides enhance the activation of complement system and antibody production [13]. The present study was carried out to evaluate the effect of Schisandra chinensis polysaccharides on Mycobacterium tuberculosis infection in a rat model of TB.

\section{EXPERIMENTAL}

\section{Animals}

Female albino rats (6 - 7 weeks old; weighing 200 - $250 \mathrm{~g}$ ) were procured from Shanghai Medical College, China. The animals were housed under standard conditions (temperature: $25 \pm 2{ }^{\circ} \mathrm{C}$, humidity: $60 \pm 5 \%$, and $12 \mathrm{~h}$ light/dark cycle) as per standard guidelines. They were kept for the period of one week for the acclimatized to laboratory conditions. All the procedure involved in the study was approved by institutional ethical committee of Wuhan Red Cross Hospital, China (no. IAEC/WRCH/2016/19). The study followed the guidelines of Association for the Assessment and Accreditation of Laboratory Animal Care International (AAALAC) for experimentation and animal use [14].

\section{Induction of TB}

M. tuberculosis H37Rv was isolated with nutrient broth for 14 days and Acrodisk filter no. 4650 was used to filter the broth. The filtered bacillary solution was used for subsequent studies. A Glas-Colaerosol generator was used for preparing an aerosol form of the TB strain which was administered to the rats. Approximately, 500 bacilli were administered to each rat through the aerosol which contained 107 CFU of H37Rv bacilli/5 mL. Five groups of rats were used (10 rats/group): normal control, TB control, $25 \mathrm{mg} / \mathrm{kg}$ SCPP11, $50 \mathrm{mg} / \mathrm{kg}$ SCPPII, and $100 \mathrm{mg} / \mathrm{kg}$ SCPPII. The treatments were given for four weeks.

\section{Colony-forming unit assay}

The animals were sacrificed and lung tissue was excised from each rat and used to prepare a tissue homogenate in sterile saline solution. Ogawa slant medium (1\%) was used to dilute $100 \mu \mathrm{L}$ of the lung homogenate. Colonies of H37Rv bacilli were cultured in the same medium at $37{ }^{\circ} \mathrm{C}$ for 4 weeks, after which the colonies were counted.

\section{ELISA assay}

ELISA kits were used for the determination of concentration of inflammatory cytokines (IL-4, IL12, TNF- $\alpha$, iNOS and IFN- $\mathrm{y}$ ) in the lung tissue homogenate as per the manufacture of the kit.

\section{Flow cytometry}

The isolation pulmonary mononuclear cells and fluorescence-activated cell sorter staining were carried out as previously described [15]. Monocytic and lymphocytic cell-specific monoclonal antibodies were used to stain the cells at $4{ }^{\circ} \mathrm{C}$ for $20 \mathrm{~min}$. The antibodies used were anti-rat V65 ( $\gamma / \delta T$-cell), R73 ( $\alpha / \beta$ T-cell), 10/78 (NK cell and T-cell), W3/25 (CD4 T-cell), fluorescein isothiocyanate-conjugated ED1 (CD68, dendritic cell/macrophage/monocyte); OX8 (CD8) and OX52 (CD6, T lymphocyte). The mononuclear cells were analyzed with Cell Quest software.

\section{Statistical analysis}

All data are expressed as mean \pm standard deviation (SD). Statistical analysis was performed using one way analysis of variance (ANOVA). Post-hoc comparison of means was carried out by Dunnett's post hoc test (Gradpad Prism 6.1, CA, USA). The level of statistical significance was set at $p<0.05$.

\section{RESULTS}

\section{Effect of Schisandra chinensis polysaccha- rides on M. tuberculosis colonies}

The effect of Schisandra chinensis polysaccharides on the number of colonies of $M$. 
tuberculosis in the lung tissue homogenate of TB-infected rats is shown in Figure 1. The CFU of $M$. tuberculosis was significantly and dosedependently reduced by SCPP 11 treatment, when compared to the untreated TB control $(p<$ $0.01)$.

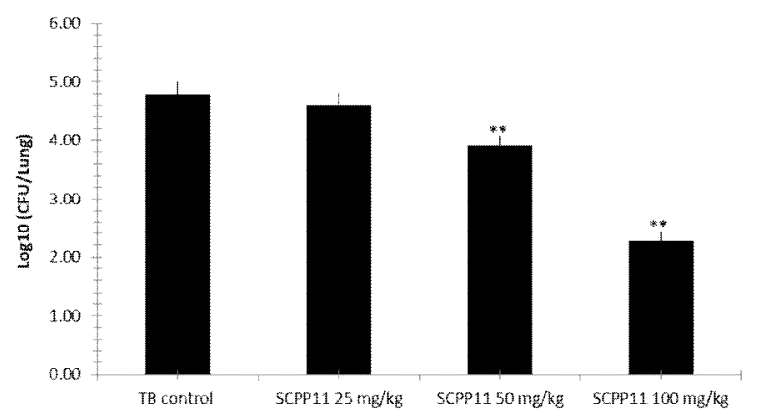

Figure 1: Effect of Schisandra chinensis polysaccharides on CFU of $M$. tuberculosis in the lung tissue homogenate of TB-infected rats. Values are expressed as mean \pm SD $(\mathrm{n}=10) ;{ }^{* \star} p<0.01$, compared to TB control group

\section{Effect of Schisandra chinensis polysaccha- rides on levels of inflammatory cytokines}

The effect of Schisandra chinensis polysaccharides on levels of IL-4, IL-12, TNF- $\alpha$, iNOS and IFN- $y$ in the lung tissue homogenate of TB-infected rats is shown in Figure 2. There was significant increase in the levels of IL-4, IL-12 and TNF- $\alpha$, and significant decreases in IFN- $y$ level in TB control group, relative to the normal control group. However SCPPII treatment resulted in significant and dose-dependent reductions in IL-4, IL-12, TNF- $\alpha$ levels, while the level of IFN- $\gamma$ was dose-dependently increased in the lung tissues, when compared to the TB control group.

\section{Effect of Schisandra chinensis polysaccha- rides on immune cell counts}

The effect of Schisandra chinensis polysaccharides on CD4, CD8, CD25, NK, $\alpha / \beta$ T cells and $\gamma / \delta T$ cellsin lung tissue homogenate of TB-infected rats is shown in Table 1.

It was observed that CD4, CD8, CD25, NK and $\alpha / \beta T$ cells were significantly enhanced in the lung tissue homogenate of the SCPP11-treated group, when compared to the TB control group of rats $(p<0.05 ; p<0.01)$. However, SCPII had no noticeable effect on the number of $y / \delta T$ cells in lung tissue homogenate of TB-infected rats.

\section{DISCUSSION}

The present study evaluated the effect of
Schisandra chinensis polysaccharides on TBinfected rats. The TB was induced by administration of colonies of tubercle bacilli through inhalation, prior to a 4-week administration of SCPP11. The effects of
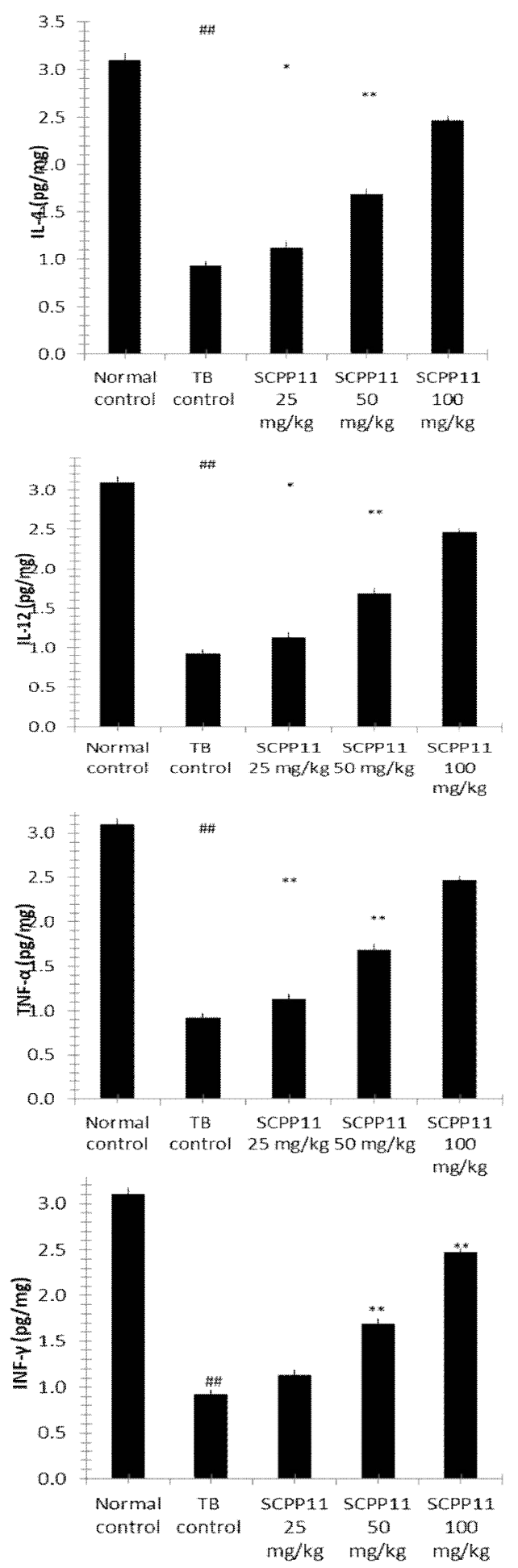

Figure 2: Effect of Schisandra chinensis polysaccharides on inflammatory cytokines in the lung tissue homogenate of TB-infected rats. Values are expressed as mean \pm SD $(n=10) ;{ }^{\#} p<0.01$, compared to normal control group; ${ }^{* *} p<0.01$, compared to TB control group 
Table 1: Effect of Schisandra chinensis polysaccharides on the levels of immune cells in lung tissue homogenate of TB-infected rats

\begin{tabular}{|c|c|c|c|c|}
\hline Group & TB control & $\begin{array}{l}\text { SCPP11 } \\
25 \mathrm{mg} / \mathrm{kg}\end{array}$ & $\begin{array}{c}\text { SCPP11 } \\
50 \mathrm{mg} / \mathrm{kg}\end{array}$ & $\begin{array}{c}\text { SCPP11 } \\
100 \mathrm{mg} / \mathrm{kg}\end{array}$ \\
\hline CD4 & $1.13 \pm 0.14$ & $1.82 \pm 0.21^{*}$ & $2.61 \pm 0.18^{\star \star}$ & $4.27 \pm 0.11^{* *}$ \\
\hline CD8 & $1.96 \pm 0.23$ & $2.31 \pm 0.16$ & $2.86 \pm 0.24^{\star *}$ & $3.49 \pm 0.28^{* *}$ \\
\hline CD25 & $0.21 \pm 0.01$ & $0.37 \pm 0.03^{*}$ & $0.79 \pm 0.06^{\star *}$ & $1.16 \pm 0.16^{\star \star}$ \\
\hline NK & $1.27 \pm 0.15$ & $2.11 \pm 0.21^{*}$ & $3.62 \pm 0.37^{\star *}$ & $5.72 \pm 0.42^{* *}$ \\
\hline$\alpha / \beta$ T cell & $2.14 \pm 0.16$ & $2.97 \pm 0.19^{*}$ & $3.52 \pm 0.22^{\star *}$ & $5.38 \pm 0.41^{* *}$ \\
\hline ү/ठ T cell & $0.36 \pm 0.02$ & $0.31 \pm 0.04$ & $0.38 \pm 0.07$ & $0.34 \pm 0.02$ \\
\hline
\end{tabular}

SCPP11 on CFU of tubercle bacilli, cytokines and immune cells in the lung tissue of TB infected rats were determined. Treatment with SCPP11 significantly decreased tubercle bacilli colonies, relative to the TB control group. This result is in agreement with a previous report [14].

Studies have shown that the expressions of the inflammatory cytokines IL-4, IL-12, TNF- $\alpha$ and IFN-y are altered in TB [15]. It is known that Th1cells mediate TB- associated immunological responses [16]. They activate macrophages by secreting IFN- $\mathrm{\gamma}$, thereby enabling them to destroy invading microorganisms [17]. Moreover IL-10 and IL-4 which participate in humoral immunity are secreted by Th2 cells [18].

In the present study, it was observed that treatment with SCPP11 attenuated the altered levels of cytokines in the lung tissues of TBinfected rats. Moreover, immune cells were lower in the TB-infected rats, which is consistent with the immune cell profiles of TB patients [19]. However, treatment with SCPP11 significantly boosted the populations of CD4, CD8, CD25, NK and $\alpha / \beta$ T-cells in the lung tissue, relative to the untreated TB control group.

\section{CONCLUSION}

The results of the present investigation provide evidence that Schisandra chinensis polysaccharides enhance cellular and humoral immunity, thereby reducing the growth of TB bacilli. Thus, these polysaccharides possess the potential for application in the clinical management of TB.

\section{DECLARATIONS}

\section{Acknowledgement}

All the authors are thankful to Wuhan Red Cross Hospital, China for providing the required facilities.

\section{Conflict of interest}

No conflict of interest is associated with this work.

\section{Contribution of authors}

We declare that this work was done by the authors named in this article and all liabilities pertaining to claims relating to the content of this article will be borne by the authors. Jian Huang performed the experiments and wrote the report, Li Ren designed the project, supervised the experiments and wrote the manuscript, Shaobin Zhang and Ze Peng analysed the data and provided comments.

\section{REFERENCES}

1. Centis R, D'Ambrosio L, Zumla A, Migliori GB. Shifting from tuberculosis control to elimination: Where are we? What are the variables and limitations? Is it achievable? Int J Infect Dis. 2017; 56: 30-33.

2. Tombolyn M, Chiller T, Eisele H, Gress R, Sepkowitz K, Storek J, Wingard JR, Young JA, Boeckh MJ; Center for International Blood and Marrow Research; National Marrow Donor program; European Blood and Marrow Transplant Group; American Society of Blood and Marrow Transplantation; Canadian Blood and Marrow Transplant Group; Infectious Diseases Society of America; Society for Healthcare Epidemiology of America; Association of Medical Microbiology and Infectious Disease Canada; Centers for Disease Control and Prevention. Guidelines for preventing infections complications among hematopoietic stem cell transplantation recipients: a global perspective. Biol Blood Marrow Transplant 2009; 15: 1143-23810.

3. Guirado E, Schlesinger LS, Kaplan G. Macrophages in Tuberculosis: Friend or Foe. Semin Immunopathol. 2013; 35: 563-583.

4. Weiss G, Schaible UE. Macrophage defense mechanisms against intracellular bacteria. Immunol Rev 2015; 264: 182-203.

5. Lu SL, Kuo CF, Chen HW, Yang YS, Liu CC, Anderson $R$, Wu JJ, Lin YS. Insufficient Acidification of Autophagosomes Facilitates Group A Streptococcus 
Survival and Growth in Endothelial Cells. Finlay BB, Ed. mBio. 2015; 6: e01435-15.

6. Palomino JC, Martin A. Drug Resistance Mechanisms in Mycobacterium tuberculosis. Antibiotics. 2014; 3: 317340.

7. Ehrt S, Schnappinger D. Mycobacterial survival strategies in the phagosome: Defense against host stresses. Cell Microbiol. 2009; 11: 1170-1178.

8. Hu J, Mao C, Gong X, Lu T, Chen H, Huang Z, Cai B. Simultaneous determination of eleven characteristic lignans in Schisandra chinensis by high-performance liquid chromatography. Pharmacogn Mag 2013; 9(34): 155-161.

9. Szopa A, Ekiert R, Ekiert H. Current knowledge of Schisandra chinensis (Turcz.) Baill. (Chinese magnolia vine) as a medicinal plant species: a review on the bioactive components, pharmacological properties, analytical and biotechnological studies. Phytochem Rev 2017; 16(2): 195-218.

10. Panossian A, Wikman G. Pharmacology of Schisandra chinensis Bail: an overview of Russian research and uses in medicine. J Ethnopharmacol 2008; 118: 183212.

11. Chen $Y$, Tang J, Wang $X$, Sun F, Liang $S$. An immunostimulatory polysaccharide (SCP-lla) from the fruit of Schisandra chinensis (Turcz.) Baill. Int $\mathrm{J}$ Biol Macromol. , 2012; 50: 844-848.

12. Sundberg-Kövamees $M$, Grunewald J, Wahlström J, Immune cell activation and cytokine release after stimulation of whole blood with pneumococcal Cpolysaccharide and capsular polysaccharides. Int $J$ Infect Dis 2016; 52: 1-8.

13. Ganguly $T$, Johnson JB, Kock ND, Parks GD, Deora R. The Bordetella pertussis Bps polysaccharide enhances lung colonization by conferring protection from complement-mediated killing. Cell Microbiol 2014; 16(7): $1105-1118$.

14. Guide for the Care and Use of Laboratory Animals: Eighth Edition Committee for the Update of the Guide for the Care and Use of Laboratory Animals; National Research Council. 2010; ISBN: 0-309-15401-4.

15. Tomlinson MJ, Tomlinson S, Yang XB, Kirkham J. Cell separation: Terminology and practical considerations. J Tissue Eng. 2013; 4: 2041731412472690.

16. Yamada H, Mizuno S, Ross AC, Sugawara I. Retinoic Acid Therapy Attenuates the Severity of Tuberculosis While Altering Lymphocyte and Macrophage Numbers and Cytokine Expression in Rats Infected with Mycobacterium Tuberculosis. J Nutr. 2007; 137(12): 2696-2700.

17. Domingo-Gonzalez R, Prince O, Cooper A, Khader S. Cytokines and Chemokines in Mycobacterium tuberculosis infection. MicrobiolSpectr. 2016; 4(5): 10.1128/microbiolspec. TBTB2-0018-2016.

18. Cooper AM. Cell mediated immune responses in Tuberculosis. Annu Rev Immunol 2009; 27: 393-422.

19. Weiss G, Schaible UE. Macrophage defense mechanisms against intracellular bacteria. Immunol Rev 2015; 264(1): 182-203.

20. Raphael I, Nalawade S, Eagar TN, Forsthuber TG. T cell subsets and their signature cytokines in autoimmune and inflammatory diseases. Cytokine 2015; 74(1): 5-17.

21. De Almeida AS, Fiske CT, Sterling TR, Kalams SA. Increased Frequency of Regulatory $T$ Cells and $T$ Lymphocyte Activation in Persons with Previously Treated Extrapulmonary Tuberculosis. Clin Vaccn Immunol 2012; 19: 45-52. 